\title{
Role of serum lipoprotein (a) in type 2 diabetes mellitus and its association with glycemic control
}

\author{
Kavitha MM¹, JG Ambekar ${ }^{2}$, Nilima Dongre ${ }^{3}$, Kashinakunti SV ${ }^{4, *}$ \\ ${ }^{1}$ PhD Scholar, ${ }^{2}$ Professor, ${ }^{3}$ Associate Professor, Dept. of Biochemistry, BM Patil Medical College, BLDE Deemed to be \\ University, Vijayapura, Karnataka, ${ }^{4}$ Professor, Dept. of Biochemistry, S Nijalingappa Medical College, Bagalkot,
}

Karnataka, India

*Corresponding Author:

Email: mekch@rediffmail.com

Received: $30^{\text {th }}$ April, 2018

Accepted: $24^{\text {th }}$ May, 2018

\begin{abstract}
Diabetes mellitus (DM) is an established risk factor for cardiovascular disease. At present global risk assessment, lipid profile is only the blood test routinely recommended most commonly. Increased lipoprotein (a) [Lp(a)] contributing factor to accelerated development of macrovascular complications in DM. However Lp(a) and hsCRP evaluation may have the potential to improve cardiovascular risk prediction when used in addition to traditional lipid profile. Hence the study was undertaken to estimate the serum lipoprotein (a), lipid profile, lipid ratios and hsCRP in diabetic patients and their association with glycemic control. Within the diabetic patients we examined Lp(a) levels among controlled and uncontrolled diabetic individuals.

Materials and Methods: An observational study comprises of 150 participants. 75 were type 2 diabetic patients and 75 were healthy controls. Diabetic patients were further sub classified into good and poor glycemic control group depending on their HbA1c levels $7.5 \%$ as cut-off value. Fasting venous blood sample was collected and used for analysis of fasting glucose, lipoprotein (a), lipid profile, high sensitive $\mathrm{C}$ reactive protein (hsCRP) and glycosylated hemoglobin (HbA1c).

Results: A significant increase $(\mathrm{p}<0.05)$ in $\mathrm{Lp}(\mathrm{a}), \mathrm{TG}, \mathrm{LDL}$, hsCRP and Lipid ratios and significant decrease in HDL in diabetic patients compared to controls. Subjects with poor glycemic control subjects showed significant increase in FBS, HbA1c, TG and hsCRP. Even though, the Lp(a) increased in poor controlled diabetics, but it was not statistical significant. HbA1c shows positive correlation with FBS, TG, HDL, hsCRP and TG/HDL in diabetic patients.

Conclusion: The study helps in identification of at risk individuals for CAD beyond the routinely done lipid profile especially in insufficient resource situations. In our study we have higher levels of Lp(a), hsCRP and other atherogenic risk factors cluster more in diabetic patients compared to healthy controls. FBS, TG, hsCRP and TG/HDL are positively correlated with HbA1c. Thus Lp(a) and hsCRP evaluation may have the potential to improve cardiovascular risk prediction when used in addition to traditional lipid profile in diabetic patients. Poor glycemic control subjects have significantly higher hsCRP and TGs compared to good glycemic controls. There is no effect of glycemic control on $\mathrm{Lp}(\mathrm{a})$ levels, hence $\mathrm{Lp}(\mathrm{a})$ is independent risk factor for CAD in diabetic patients.
\end{abstract}

Keywords: Lipoprotein (a), Glycemic contol, Diabetes mellitus.

\section{Introduction}

Diabetes mellitus (DM) is a chronic noncommunicable metabolic disorder and is also known as "Iceberg" disease. India has the largest number of diabetic people with 50.8 million and is said to be diabetes capital of the world. ${ }^{1}$ Among noncommunicable diseases diabetes is considered as high in morbidity and mortality rates. According to WHO reports diabetes will be the seventh cause of death by the end of 2030. As per study $50 \%$ of diabetics die due to cardiovascular disease. Diabetic subjects are known to have a two to four times increased risk of developing coronary artery disease (CAD) and CAD occurs two to three decades earlier in diabetic subjects as compared to nondiabetic subjects. ${ }^{2}$ It was considered DM is an established risk factor for cardiovascular disease (CVD) and is considered to be CVD equivalent. Thus WHO in 2016 put an effort for sensitizing and bringing awareness about diabetes among people all over the world with theme "Beat Diabetes".

Abnormalities in lipid metabolism i.e dyslipidemia and lipoproteins are the established traditional risk factors for CAD. Elevated cholesterol (TC), triglyceride (TG), low density lipoprotein cholesterol (LDL-C) and low levels of high density lipoprotein cholesterol (HDL-C) are characteristic of typical dyslipidemia. Several intervention studies reveled reduction of serum TC and TG levels inturn reduction of mortality due to $\mathrm{CAD}^{3,4}$

Lipoprotein (a) $[\mathrm{Lp}(\mathrm{a})]$ type of low density lipoprotein cholesterol (LDL-C) called little rascal. It was first identified by $\mathrm{K}$ Berg in $1963 .^{5} \mathrm{Lp}(\mathrm{a})$ composed of an LDL-C like particle and apolipoprotein(a) which is covalently bound to apo $\mathrm{B}$ of LDL-C particle. $\mathrm{Lp}(\mathrm{a})$ is structural analogue and competitive inhibitor of plasminogen leading to impaired fibrinolysis. $L p(a)$ accumulates in the vessel wall; inhibits binding of plasminogen to cell surface. This inhibition also promotes proliferation of smooth muscle cells. Hence $\operatorname{Lp}(\mathrm{a})$ has atherogenic and thrombotic properties. ${ }^{6}$ Studies reveal that diabetic patients are reported to have higher $\operatorname{Lp}(\mathrm{a})$ values than non diabetic controls and still higher values found in diabetics with complications. ${ }^{7,8}$ Increased Lp(a) levels 
confer genetic predisposition to CVD and may be related to accelerated atherogenesis in DM.

Recent data support that lipid ratios are more meaningful than individual lipid parameters. They help in early prevention and diagnosis of CHD than the individual serum lipids. ${ }^{9}$

High sensitivity C-reactive protein (hsCRP) is an acute phase protein, biomarker of inflammation and as an independent predictor for CAD. hsCRP levels increase with inflammation and insulin resistance. Measurement of hsCRP may be considered marker for better prediction of cardiovascular risk. ${ }^{10}$

Glycosylated hemoglobin (HbA1c) reflects the cumulative blood glucose over period of 8-10 weeks. It is an important indicator of long term glucose control and thus part of continuing care in diabetics. ${ }^{11,12}$ Elevated HbA1c concentration has been considered an independent risk factor for coronary artery disease in diabetic patients. ${ }^{13}$ It is reported that good glycemic control is associated with reduction in CVD. ${ }^{14}$ Studies reveal that decrease $L p(a)$ levels with improved glycemic control in diabetic patients. ${ }^{15}$

There are very few and controversial data on $L p(a)$ in diabetics and its relationship with glycemic control in Indian population. Hence the present study was conducted to estimate the serum Lp(a) levels, lipid profile, lipid ratios and hsCRP in diabetic patients and to compare with healthy controls. Within the diabetic patients we examined Lp(a) levels among controlled and uncontrolled diabetic individuals by taking HbA1c $7.5 \%$ as cut-off value and also to see the relationship between $\mathrm{Lp}(\mathrm{a})$, lipid profile, lipid ratios and hsCRP with glycemic control.

\section{Materials and Methods}

This is a hospital based observational case-control study, conducted in the department of Biochemistry, S Nijalingappa Medical College and Hanagal Sri Kumareshwara Hospital Research Centre, Bagalkot, a teaching Centre in Karnataka, India. The study protocol was approved by institutional ethics committee (IEC). Study was conducted over a period of one year from January to December 2016. The study comprises of 150 subjects, 75 were clinically diagnosed diabetic patients attending the medical OPD and admitted patients. Age and sex matched 75 healthy controls of the age group between 30 to 60 years. Diabetes was diagnosed on the basis of WHO criteria (FBS > $126 \mathrm{mg} / \mathrm{dL}$ or PPBS > $200 \mathrm{mg} / \mathrm{dL}$ or $\mathrm{HbA} 1 \mathrm{c}>6.5 \%$ ). Diabetic patients were further subdivided into two groups as good and poor glycemic control depending on HbA1c levels $7.5 \%$ as cut-off levels. Patients with thyroid disorders, nephrotic syndrome, chronic liver, renal diseases, diabetics with any complications and pregnant ladies were excluded from the study.

Informed written consent was taken from all participants. All care was taken to maintain the confidentiality of the patients as per Helsinki declaration.
For each patient detail history was taken, general physical examination and anthropometric measurements like height and weight are recorded. Body mass index (BMI) was calculated using the formula $\mathrm{Wt}(\mathrm{Kg}) / \mathrm{Ht}(\mathrm{m})$.

Under aseptic precaution $5 \mathrm{~mL}$ of fasting venous blood was drawn. Out of this $2 \mathrm{~mL}$ was EDTA sample used for estimation of $\mathrm{HbA} 1 \mathrm{c}$ by high performance liquid chromatography (HPLC) method in D-10 BioRad instrument. Remaining $3 \mathrm{~mL}$ was allowed to clot and serum was separated. The serum was used for analysis of biochemical parameters like fasting blood glucose (FBS), lipid profile, lipoprotein (a) and hsCRP. Glucose was estimated by glucose oxidase and peroxidase method. TG's by glycerol phosphate method, HDL-C estimated by direct method. LDL-C was calculated by Friedewald's formula i.e LDL=TCTG/5-HDL. Lp(a) and hsCRP was estimated by immunoturbidemetric method. All parameters were measured in fully automated analyser, Biosystem A25 using Biosystem kits. Lipid ratios were calculated i.e TC/HDL, LDL/HDL, and TG/HDL.

\section{Statistical Analysis}

Statistical analysis was carried out using software SPSS version 19. Quantitative data were expressed as mean \pm SD. Student ' $t$ ' test was applied for comparison of two groups and Pearson's correlation test was applied for correlation. $\mathrm{p}<0.05$ is considered as statistically significant.

\section{Results}

Demographic characters of cases and control was shown in table 1. There was significant increase in BMI, FBS and HbAlc in cases compared to controls. There was no difference ( $\mathrm{p}=0.16)$ in age among two groups.

Table 2 shows the comparison of lipid profile, $\mathrm{Lp}(\mathrm{a})$, hsCRP and lipid ratios between cases and controls. In the present study diabetic subjects have significantly higher $(p<0.05)$ serum TG's, LDL-C, $\mathrm{Lp}(\mathrm{a})$ and hsCRP compared to controls. There was significant decrease in HDL-C levels in cases compared to controls. There was significant increase $(\mathrm{p}<0.000)$ in lipid ratios in diabetics compared to controls.

Comparison of lipid profile, Lp(a), hsCRP and lipid ratios among type 2 diabetic patients with good and poor glycemic control are depicted in table 3. Diabetic patients with poor glycemic control showed significant $(\mathrm{p}=0.0001)$ increase in FBS, HbAlc, TGs, and hsCRP compared to good glycemic control group. Although, the $\mathrm{Lp}$ (a) levels in poor glycemic patients are increased compared to good glycemic control subjects $(29.8 \pm$ 16.47 , vs $23.69 \pm 14.23$ ) it was not statistical significant.

Pearson correlation of $\mathrm{HbAlc}$ with FBS, lipid profile, $\mathrm{Lp}(\mathrm{a}), \mathrm{hsCRP}$ and lipid ratios was shown in table 4. There was significant positive correlation between HbAlc with FBS $(r=0.38, p=0.001)$ Fig. 1 , TGs $(r=$ $0.234, \mathrm{p}=0.04), \mathrm{HDL}(\mathrm{r}=0.277, \mathrm{p}=0.01)$ hsCRP $(\mathrm{r}=0.780$, $\mathrm{p}=0.0001)$ Fig. 2 and TG/HDL ( $\mathrm{r}=0.14, \mathrm{p}=0.001)$. 
Table 1: Table showing clinical characteristics, FBS and HbA1c in controls and cases

\begin{tabular}{|l|c|c|c|c|}
\hline & Control N=75 & Cases N=75 & t & p-value \\
\hline Age in Year & $52.74 \pm 16.69$ & $56.45 \pm 16.3$ & 1.39 & 0.16 \\
\hline $\begin{array}{l}\text { BMI } \\
\text { Kg/m }\end{array}$ & $24.98 \pm 1.41$ & $26.34 \pm 2.08$ & 4.61 & $0.000^{* *}$ \\
\hline $\begin{array}{l}\text { FBS } \\
\mathrm{mg} / \mathrm{dL}\end{array}$ & $87.79 \pm 17.37$ & $165.73 \pm 58.91$ & 10.98 & $0.000^{* *}$ \\
\hline $\mathrm{HbA} 1 \mathrm{c} \%$ & $5.28 \pm 0.61$ & $8.51 \pm 1.96$ & 13.58 & $0.000^{* *}$ \\
\hline
\end{tabular}

** - Highly significant

Table 2: Table showing the lipid profile, $L p(a)$, hsCRP and lipid ratios in control and cases

\begin{tabular}{|l|c|c|c|c|}
\hline Parameters & Control N=75 & Cases N=75 & t & P value \\
\hline $\begin{array}{l}\text { TC } \\
\mathrm{mg} / \mathrm{dL}\end{array}$ & $153.97 \pm 35.1$ & $163.49 \pm 47.10$ & 1.45 & 0.16 \\
\hline $\begin{array}{l}\text { TGs } \\
\mathrm{mg} / \mathrm{dL}\end{array}$ & $112.32 \pm 54.95$ & $128.98 \pm 41.26$ & 2.09 & $0.03^{*}$ \\
\hline $\begin{array}{l}\mathrm{HDL}-\mathrm{C} \\
\mathrm{mg} / \mathrm{dL}\end{array}$ & $39.2 \pm 9.69$ & $33.17 \pm 9.88$ & 3.71 & $0.002^{* *}$ \\
\hline $\begin{array}{l}\text { LDL-C } \\
\mathrm{mg} / \mathrm{dL}\end{array}$ & $92.3 \pm 28.74$ & $104.52 \pm 42.1$ & 2.07 & $0.03^{*}$ \\
\hline $\begin{array}{l}\text { Lp(a) } \\
\mathrm{mg} / \mathrm{dL}\end{array}$ & $17.20 \pm 3.98$ & $26.87 \pm 15.63$ & 5.19 & $0.001^{* *}$ \\
\hline $\begin{array}{l}\mathrm{hsCRP} \\
\mathrm{mg} / \mathrm{L}\end{array}$ & $1.28 \pm 0.37$ & $3.93 \pm 0.98$ & 21.71 & $0.001^{* *}$ \\
\hline TC/HDL & $4.04 \pm 0.95$ & $5.22 \pm 1.73$ & 5.19 & $0.001^{* *}$ \\
\hline LDL/HDL & $2.43 \pm 0.81$ & $3.37 \pm 1.51$ & 4.75 & $0.001^{* *}$ \\
\hline TG/HDL & $3.01 \pm 1.5$ & $4.27 \pm 1.84$ & 4.11 & $0.001^{* *}$ \\
\hline
\end{tabular}

Table 3: Table showing the lipid parameters, Lp(a), hsCRP and lipid ratios in good and poor glycemic control diabetic patients

\begin{tabular}{|l|c|c|c|c|}
\hline Parameters & $\begin{array}{c}\text { HbA1c }<\mathbf{7 . 5} \% \\
\mathbf{N = 3 6}\end{array}$ & $\begin{array}{c}\text { HbA1c }>\mathbf{7 . 5 \%} \\
\mathbf{N}=\mathbf{3 9}\end{array}$ & t value & P value \\
\hline FBS mg/dL & $136.81 \pm 31.92$ & $182.41 \pm 65.46$ & 4.2 & $0.0001 *$ \\
\hline HbA1c \% & $6.98 \pm 0.45$ & $9.84 \pm 1.65$ & 13.4 & $0.0001 *$ \\
\hline TC mg/dL & $162.06 \pm 48.31$ & $160.78 \pm 46.83$ & 1.06 & 0.84 \\
\hline TG mg/dL & $125.74 \pm 32.83$ & $137.36 \pm 47.38$ & 2.08 & $0.03 *$ \\
\hline HDL-C mg/dL & $35.83 \pm 8.64$ & $30.18 \pm 9.68$ & 1.25 & 0.49 \\
\hline LDL-C mg/dL & $101.13 \pm 61.03$ & $103.2 \pm 52.67$ & 1.34 & 0.37 \\
\hline Lp(a) mg/dL & $23.69 \pm 14.23$ & $29.8 \pm 16.47$ & 1.257 & 0.49 \\
\hline hsCRP mg/L & $3.29 \pm 0.56$ & $4.57 \pm 0.93$ & 2.758 & $0.003 *$ \\
\hline TC/HDL & $4.52 \pm 1.83$ & $5.32 \pm 1.4$ & 1.653 & 0.1 \\
\hline LDL/HDL & $2.82 \pm 0.94$ & $3.42 \pm 1.0$ & 1.403 & 0.3 \\
\hline TG/HDL & $3.51 \pm 1.29$ & $4.51 \pm 2.1$ & 3.062 & $0.001 * *$ \\
\hline$*$ - Statistical significant, **- Highly significant & & & \\
\hline
\end{tabular}

Table 4: Correlation of HbA1c with other lipid parameters

\begin{tabular}{|c|c|c|c|}
\hline \multirow{4}{*}{ HbA1c } & Parameters & $\mathbf{r}$ & p-value \\
\cline { 2 - 4 } & FBS & 0.380 & $0.001 *$ \\
\cline { 2 - 4 } & TC & 0.182 & 0.114 \\
\cline { 2 - 4 } & TG & 0.234 & $0.043 *$ \\
\cline { 2 - 4 } & HDL-C & 0.277 & $0.01 *$ \\
\cline { 2 - 4 } & LDL-C & 0.142 & 0.218 \\
\cline { 2 - 4 } & hsCRP & 0.780 & $0.000 *$ \\
\cline { 2 - 4 } & Lp(a) & 0.125 & 0.287 \\
\cline { 2 - 4 } & TC/HDL & 0.019 & 0.873 \\
\cline { 2 - 4 } & LDL/HDL & 0.018 & 0.87 \\
\cline { 2 - 4 } & TG/HDL & 0.243 & $0.03 *$ \\
\hline * Statistical significance & & \\
\hline
\end{tabular}




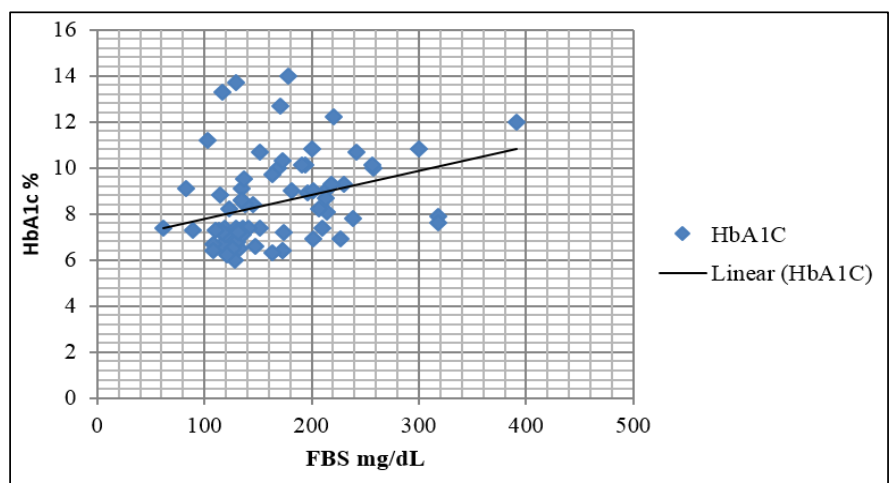

Fig. 1: Correlation graph of HbA1c with FBS in diabetic patients

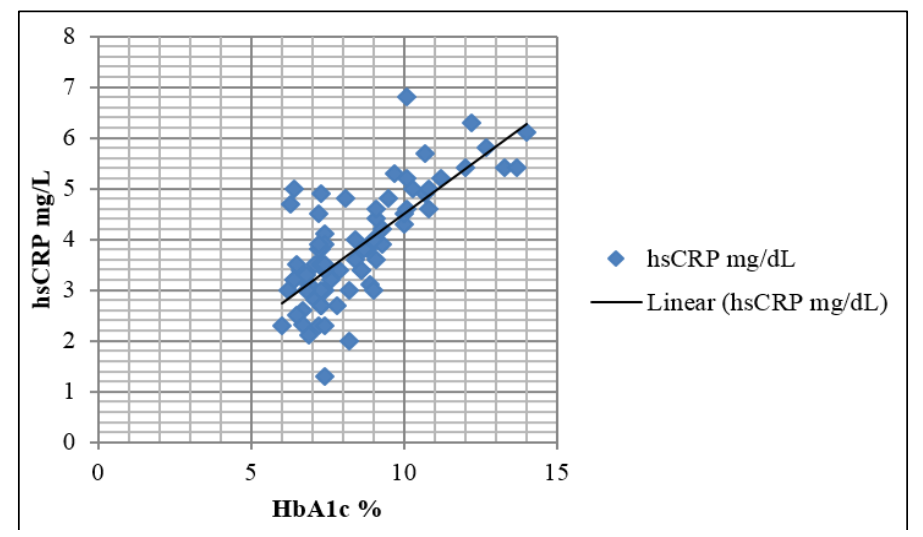

Fig. 2: Correlation graph of hsCRP with HbA1c in diabetic patients

\section{Discussion}

In our study FBS and $\mathrm{HbA1c}$ are significantly increased in diabetic patients compared to controls. Increased TG's, LDL-C and decreased HDL-C are well known risk factors for $\mathrm{CAD}$ in diabetic patients. In our study we did not find any difference in TC. High prevalence of dyslipidemia in subjects with type 2 diabetes mellitus, our study is in accordance with other studies. ${ }^{16,17}$ In diabetic subjects, high TG levels tend to coexist with low HDL levels. ${ }^{18,19}$

$\mathrm{Lp}(\mathrm{a})$ is variant of LDL-C emerging as a strong biomarker of CAD. Our results show that diabetic patients have high $\mathrm{Lp}$ (a) levels compared to controls. The increased $L p(a)$ levels in diabetic subjects may be due to increased concentration of glycated $\mathrm{Lp}(\mathrm{a})$ in the circulation. $^{20,21}$ Glycosylation increases the half-life of lipoproteins i.e $\operatorname{Lp}(a)$. Reports say that $L p(a)$ levels above $20 \mathrm{mg} / \mathrm{dL}$ are associated with high risk of CAD. ${ }^{22}$ A south Indian study on 300 participants, reports $L p(a)$ had an independent association with $C A D$ in type 2 diabetes patients. An increase $L p(a)$ levels was found to be associated with increase in carotid intimal thickness. Hence, $\mathrm{Lp}(\mathrm{a})$ is associated with CAD even at an early stage of atherosclerosis. ${ }^{23}$

A cross sectional study by Anthonia $\mathrm{OO}^{24}$ et al carried out on 200 Nigerian patients with type 2 DM, reported that elevated serum $L p(a)$ levels are higher in subjects with DM than in people without DM. It also showed positive association with most of the atherogenic profile parameters in type 2 DM individuals. A study by Gazzaruso $\mathrm{C}$ et $\mathrm{al}^{25}$ reported that estimation of $\mathrm{Lp}(\mathrm{a})$ and apo (a) phenotypes may be used not only as predictor of CAD and also predictor of CAD severity in type 2 diabetic patients. A south Indian study by Mohan $\mathrm{V}$ et $a l,{ }^{26}$ reports that $\mathrm{Lp}(\mathrm{a})$ is an independent association with CAD in type-2 diabetic patients. Haffner et al $^{14}$ says contradictory statement that, slightly lower $L p(a)$ levels in diabetic patients than non diabetic subjects and there was no statistical significance.

Data support that lipid ratios have been reported more sensitive in reflecting the morbidity and severity of CHD than individual lipid parameters. Our study shows that there was significant increase in lipid ratios in diabetic patients compared to controls. Among the lipid ratios TG/HDL showed positive correlation with HbA1c. According to Shai et al ${ }^{27}$ TC/HDL, LDL/HDL and apoB/apoA ratios are more susceptible to increased CVD mortality than individual lipid. According to Imran AS et $\mathrm{al}^{28}$ atherogenic index (AI) can be used to indicate the presence of increased cardiovascular risk in patients with type $2 \mathrm{DM}$ and as a guide for the aggressive therapeutic approach. The TG/HDL ratio is cheap and easy to calculate and is a good predictor of LDL size. In current strategies of global risk assessment, lipid profile is only the blood test routinely recommended most commonly in all setups. Calculation of lipid ratios is very easy and can be done 
routinely from lipid profile parameters especially in Indian set up where new tests are not routinely possible because of cost factor.

We know that hsCRP is the inflammatory biomarker. In our study there was significant increase in hsCRP in diabetic patients compared to controls. Evaluation of hsCRP may have potential to improve cardiovascular risk prediction when used along with other traditional lipid profile. It was considered as single strongest predictor of risk. ${ }^{29}$ In our study it was also increased in poorly controlled diabetic individuals compared to good glycemic diabetic individuals. It was positively correlated with $\mathrm{HbA1c}$ levels. Many trials and studies reveal that hsCRP is an independent predictor of future cardiovascular events in diabetes and significantly correlates with HbA1c. ${ }^{30,31}$

Hyperglycemia enhances glycosylation of proteins particularly lipoproteins. Glycosylation of LDL has been shown to enhance its susceptibility to oxidation, which triggers the atherosclerotic processes. In present study subjects with poor glycemic control showed significantly higher levels of FBS, HbAlc and TGs compared to good control diabetics. Dyslipidemia increases with increasing blood glucose levels and thus cardiovascular risk would be high with poor glycemic control. ${ }^{32}$ Data revels $25 \%$ reduction in microvascular complications with improved blood glucose control in type 2 diabetics was demonstrated in United Kingdom Prospective Diabetic Study (UKPDS). ${ }^{33}$

In our study there is relatively higher $\operatorname{Lp}(\mathrm{a})$ levels in poorly controlled glycemic diabetics compared to good controls but it is not statistically significant. SS Habib ${ }^{34}$ in his study reported that diabetic patients have higher levels of Lp(a) and hsCRP. Diabetic patients with poor glycemic subjects have significantly higher hsCRP levels compared to those with good glycemic control and there is no effect of glycemic control on Lp(a) levels. Our results are in accordance with few other studies. ${ }^{35,36}$ Poorly controlled diabetes mellitus is associated with high $\mathrm{Lp}$ (a) levels and this metabolic abnormality contributes to elevated coronary risk in diabetic individuals. According to few hypotheses there is defect in the clearance of the apoprotein B-100 in diabetic individuals. Few say decrease in LDL-C in cellular metabolism in diabetes mellitus is proposed to be due to glycation of LDL particle and LDL receptors. $^{35}$ In our study there is no significant association of $\operatorname{Lp}(\mathrm{a})$ with glycemic control which is in accordance with Smaoui et al..$^{37}$

In our study there was significant positive correlation of HbA1c with FBS, TGs hsCRP and TG/HDL which are significantly associated with CVD risk factors. The findings by $\mathrm{Habib}^{30}$ and Heller ${ }^{7}$ showed that positive correlation of $\mathrm{Lp}(\mathrm{a})$ with $\mathrm{TC}$ and LDL-C but not with TGs and HDL-C. Study by Elizabath et $a l^{38}$ LDL and HDL cholesterol significantly associated with HbAlc. HDL-C was inversely associated with $\mathrm{HbA1c}$ and LDL-C positively associated with $\mathrm{HbA} 1 \mathrm{c}$ in diabetic patients.

\section{Conclusion}

Increased levels of Lp(a), hsCRP and dyslipidemia in diabetic patients compared to healthy controls. FBS, TG, HDL-C and hsCRP are positively correlated with HbA1c. Thus Lp(a) and hsCRP evaluation may help in early cardiovascular risk prediction when used in addition to other traditional lipid parameters in diabetic patients. Poor glycemic control subjects have significantly higher hsCRP and TGs compared to good glycemic controls. There is no effect of glycemic control on $\mathrm{Lp}$ (a) levels, hence $\mathrm{Lp}(\mathrm{a})$ is an independent risk factor for $\mathrm{CAD}$ in diabetic patients.

Limitation of the Study: Small sample size.

Further Scope of the Study: Genetic factor should be taken into consideration while estimating the $\mathrm{Lp}(\mathrm{a})$ levels.

Conflict of Interest: There is no conflict of interest among the authors.

\section{References}

1. IDF Diabetes Atlas, $4^{\text {th }}$ edition. International Diabetes Federation. 2009.

2. Haffner SM, Lehto S, Ronnemaa T, Pyorala K, Laakso M. Mortality from coronary heart disease in subjects with type 2 diabetes and nondiabetic subjects with and without myocardial infarction. N Engl J Med. 1998;339(4):22934.

3. Heart protection study collaborative group. MRC/BHF Heart protection study of cholesterol lowering with Simvastatin in 20536 high risk individuals: a randomized placebo controlled trial. Lancet. 2002;360(9326):7-22.

4. Rajmohan L, Deepa R, Mohan A, Mohan V. Association between isolated hypercholesterolemia, isolated hypertriglyceridemia and CAD in south Indian type 2 diabetic patients. 00-6, Indian Heart J. 200;52(4):4.

5. Berg K. A new serum type system in man the $\mathrm{Lp}(\mathrm{a})$ system. Acta Pathol Microbiol Scand. 1963;59:369-73.

6. Caplice NM, Panetta C, Peterson TE, Kleppe LS, Mueske CS, Kostner GM, Broze GJ, Simari RD. Lp(a) binds and inactivates tissue factor pathway inhibitor: a novel link between lipoproteins and thrombosis. Blood. 2001;98(10):2980-7.

7. Heller FR, Jamart J Honore P, Derue G, Novik V, Galanti L. Serum lipoprotein(a) in patients with diabetes mellitus. Diabetes Care. 1993;16(3):819-23.

8. Syed Habib MA. High risk levels of lipoprotein (a) in Pakistani patients with type 2 diabetes mellitus. Saudi Medical Journal, 2003;24(6):647-51.

9. Pan AM, Tao Z. The clinical value of part of the lipid ratio test on right coronary artery disease in patients. $J$ Clin and Exp Med. 2009;8:14-5.

10. Elkind MS, Tai W, Coates K, Paik MC, Sacco RL. High sensitive c-reactive protein, lipoprotein associated phospholipase A2 and outcome after ischemic stroke. Arch Intern Med. 2006;166:2073-80.

11. American diabetic association. Standards of medical care for patients with diabetes mellitus. Diabetes care.2000;23 (Supplment 1):S32-42. 
12. Khan HA, Sobki SH, Khan SA. Association between glycemic control and serum lipid profile in type 2 diabetic patients: HbA1c predicts dyslipidemia. Clin Exp Med. 2007;7:24-9.

13. Selvin E, Coresh J, Golden SH, Brancati FL, Folsom AR, Steffes MW. Glycemic control and coronary artery disease risk in persons with and without diabetes: the atherosclerosis risk in communities study. Arch Intern Med. 2005;165:1910-6.

14. Khaw KT, Wareham N. Glycated hemoglobin as a marker of cardiovascular risk. Curr Opin Lipidol. 2006; 17:637-43.

15. Haffner SM, Tuttle KR, Rainwater DL. Decrease Lipoprotein(a) with improved glycemic control in IDDM Subjects. Diabetes Care. 1991 Apr;14(4):302-7.

16. Ishfaq A, Tabassum A, Ganie MA, Syed M. Lipid profile in diabetes mellitus patients of Kashmir region. IJEM. 2008;12(6 \& 7):13-4.

17. Abdulbari Bener, Mahmoud Zirie, Mohammed H, Daghash, Abdulla OAA, Al-Hamaq, et al. Lipids, lipoprotein(a) profile and HbA1c among Arabian Type2 diabetic patients. Biomedical research. 2007;18(2):97102.

18. Patil M, Nirmal Kumar, Aliya Nusrath, Shubha Jayaram, Rajeshwari A. Association of HbA1c with serum lipid profile and lipoprotein (a) in type 2 diabetes mellitus. Int J Cur Res Rev. 2014;6(6):20-5.

19. Anthonia OO, Olufemi AF, Sonny C, Akinyele A. Characterization of lipid parameters in diabetes mellitus A Nigerian report. International Archives of Medicine. 2009;2:19.

20. Klaya F, Durlach V, Bertin E, Monier F, Moinboisse JC, Gillery P. Evaluation of serum glycated Lp(a) levels in non-insulin dependent diabetic patients. Clin Biochem. 1997;30:227-30.

21. Maca T, Mlekusch W, Doweik L, Budinsky AC, Bischof $\mathrm{M}$, Miner $\mathrm{E}$ et al. influence and interaction of diabetes and $L p(a)$ serum levels on mortality of patients withperipheral artery disease. Eur J Clin Invest. 2007;37:180-6.

22. Von Ec Kardstein A, Schulte H, Cullen P, Assmann G. Lipoprotein (a) further increases the risk of coronary events in men with high global cardiovascular risk. $J \mathrm{Am}$ Coll Cardiol. 2001;37(2):434-9.

23. Velmurugan K, Deepa R, Ravikumar R, Lawrence JB, Anhoo H, Senthilvelumurugan M, Enas EA, Mohan V. Relationship of $\mathrm{Lp}$ (a) with intimal medial thickness of the carotid artery in type 2 diabetic patients in south India. Diaet Med. 2003;20(6):455-61.

24. Anthonia OO, Alfred OA. Lipoprotein (a), CRP and some metabolic cardiovascular risk factors in type $2 \mathrm{DM}$ Diabetology and Metabolic Syndrome. 2010;2:51

25. Gazzaruso C, Bruno R, Pujia A et al. Lp(a), apolipoprotein polymorphism and coronary atherosclerosis severity in type 2 diabetic patients. Int $J$ of Cardiology. 2006;108(3):354-8.

26. Mohan V, Venkataraman JV. Epidemiology of Cardiovascular disease in Type-2 daibetes mellitus: The
Indian Scenario. Journal of Diabetes science and Technology, 2010;4(1):158-170.

27. Shai I, Rimm EB, Hankinson SE. Multivariate assessment of lipid parameters as predictor of coronary heart disease among postmenopausal women potential implications for clinical guideline. Circulation. 2004;110:2824-30.

28. Imran AS Imran AS, Laxmikanth B, Mariya, Rama Rao J. Lipid indices in type $2 \mathrm{DM}$ and their association with macro and micro vascular complications. Int J Med Res Health Sci. 2013;2(1):87-92.

29. Cetin I, Yildirim B, Sahin S, Sahin I, Etikan I. Serum lipid and lipoprotein levels, dyslipidemia prevalence and the factors that influence these parameters in a Turkish population living in the province of Tokat. Turk J Med Sci. 2010;40:771-82.

30. Syed Shahid Habib. Serum Lipoprotein (a) and hsCRP levels in Saudi patients with type-2 diabetes mellitus and their relationship with glycemic control. Turk J Med Sci. 2013;43:333-8.

31. Alsaeid M, Qabazard M, Shaltout A, Sharma PN. Impact of glycemic control on serum $\mathrm{Lp}(\mathrm{a})$ in Arab children with type 1 diabetes. Pediatr Int. 2001;43:246-50.

32. Ramirez LC, Pacheco CA, Lackner C et al. Lipoprotein (a) levels in diabetes mellitus: Relationship to metabolic control. ANN Intern Med. Jul;1992;1:117(1)42-7.

33. Holman RR, Paul SK, Bethel MA, Matthews Dr, neil HA. 10-yeasr follow-up of intensive glucose control in typr 2 diabetes. N Engl J Med. 2008;359:1577-89.

34. Ridker PM. C-reactive protein and prediction of cardiovascular events among those at intermediate risk: moving an inflammatory hypothesis toward consensus. $J$ Am Coll Cardiol. 2007;49(21):2129-38.

35. Habib SS, Kurdi MI, Zohair AA. Serum high sensitivity C-reactive protein and Lipoprotein (a) levels: A comparison between diabetic and nondiabetic patients with coronary artery disease. Med J Malaysia. 2011;66(2):113-6.

36. Pfutzner A, Forst T. High sensitive C-reactive protein as cardiovascular risk marker in patients with diabetes mellitus. Diabetes Technol Ther. 2006;8:28-36.

37. Smaoui M, Hanamami S, Chabba R, Attia N, Hamda KB, Masmoudi AS et al. Lipid and lipoprotein (a) concentrations in Tunisian type 2 diabetic patients; relationship to glycemic control and coronary heart disease. J Diabetes complications. 2004;18:258-63.

38. Elizabeth S, Joseph C, Sherita GH, Lori L, Boland, Frederick BL, Michael SW. Glycemic control, Atherosclerosis and risk factors for cardiovascular disease in individuals with diabetes. Diabetes care. 2005;28(8):1965-73.

How to cite this article: Kavitha MM, Ambekar JG, Dongre N, Kashinakunti SV. Role of serum lipoprotein (a) in type 2 diabetes mellitus and its association with glycemic control. Int J Clin Biochem Res. 2018;5(3):435440 . 